\title{
AsPeCtOs DA RESISTÊNCIA DE Sagittaria montevidensis AO HeRBicida Pirazosulfuron-EThyl INIBIDOR DA ALS ${ }^{1}$
}

\author{
Aspects of Sagittaria montevidensis Resistance to the ALS-Inhibiting Herbicide \\ Pirazosulfuron-Ethyl
}

CONCENÇO, G. ${ }^{2}$, NOLDIN, J. A. ${ }^{3}$, LOPES, N. F. ${ }^{4}$ e COMIOTTO, A. ${ }^{5}$

\begin{abstract}
RESUMO - Os herbicidas inibidores da enzima ALS (acetolactato sintase) possuem alta eficiência em baixas doses, baixa toxicidade para mamíferos e amplo espectro de ação, e alguns deles podem apresentar persistência prolongada no solo. Esses herbicidas caracterizam-se ainda por apresentar um único local de ação - a enzima ALS, facilitando a seleção de espécies resistentes. Geralmente, o mecanismo de resistência aos herbicidas inibidores da ALS é considerado como insensibilidade da enzima ao herbicida, ou seja, a alguma alteração no sítio de ligação herbicida-enzima. No entanto, mecanismos de tolerância de culturas aos herbicidas inibidores da ALS são observados, como as diferenças quanto a absorção, translocação e degradação, antes que o produto alcance o local de ação. O objetivo deste trabalho foi avaliar aspectos de nivel e local preferencial de absorção e a translocação do herbicida pirazosulfuronethyl, na determinação do mecanismo de resistência de um ecótipo de Sagittaria montevidensis resistente aos herbicidas inibidores da ALS. Foram instalados experimentos em BOD e em casa de vegetação. Os tratamentos foram compostos de doses exponenciais do herbicida pirazosulfuron-e thyl $\left(2^{0} \mathrm{x}, 2^{2} \mathrm{x}, 2^{4} \mathrm{x}, 2^{6} \mathrm{x}\right.$ e $2^{8} \mathrm{x}$ em relação à dose usual $-20 \mathrm{~g}$ i.a. ha $\left.{ }^{-1}\right)$, aplicadas individualmente na parte aérea, raiz e sementes de ecótipos resistente e suscetivel. Os resultados mostraram haver diferenças entre o ecótipo resistente e o suscetivel quanto ao sítio preferencial de absorção do herbicida pirazosulfuron-ethyl.
\end{abstract}

Palavras-chave: mecanismos de resistência, sagitária, translocação.

ABSTRACT - The ALS-inhibiting herbicides are highly effective when applied in low rates, presenting low toxicity to mammalians, wide control spectrum and, some of them, long soil persistence. Usually, the resistance mechanism for ALS inhibitors is due to the lack of enzyme sensitivity to the herbicide, resulting from alterations in the enzyme conformation. However, crop tolerance mechanisms are observed, such as differences in absorption, translocation and degradation before the herbicide reaches the target site. The objective of this research was to evaluate aspects related to the level and main absorption mechanism of pyrazosulfuron-ethyl to determine the resistance mechanism of an ALS-resistant $\mathbf{S}$. montevidensis ecotype. Experiments were carried out under growth chamber, and greenhouse conditions. The treatments were $2^{\circ} x$; $2^{2} x ; 2^{4} x ; 2^{6} x$ and $2^{8} x$ ( $X=$ label rate) of pyrazosulfuron-ethyl (20 g a.i. ha ${ }^{-1}$ ), applied individually on the shoots, roots and seeds of a resistant and a susceptible ecotype. The results showed some differences between susceptible and resistant ecotypes in relation to the main site of herbicide absorption.

Keywords: resistance mechanisms, giant arrowhead, translocation.

Recebido para publicação em 25.5.2006 e na forma revisada em 27.2.2007.

2 Eng.-Agr., M.Sc. em Fisiologia Vegetal, Doutorando em Fitotecnia pela Universidade Federal de Viçosa, 36570-000 Viçosa-MG bolsista CNPq, <gconcenco@yahoo.com.br>; ${ }^{3}$ Eng.-Agr., Ph.D., Pesquisador da área de Plantas Daninhas da Epagri/EEI, ItajaíSC, <noldin@epagri.rct-sc.br>; ${ }^{4}$ Eng.-Agr., Ph.D., Professor do Departamento de Botânica na Universidade Federal de Pelotas, Pelotas-RS; ${ }^{5}$ Eng.-Agr., M.Sc. em Fisiologia Vegetal, Universidade Federal de Pelotas, Pelotas-RS. 


\section{INTRODUÇÃO}

Os herbicidas inibidores da enzima ALS (ace to lactato sintase), respon sável pela biossintese dos aminoácidos valina, leucina e isoleucina (Chaleff \& Mauvais, 1984; Gazziero et al., 2006), caracterizam-se por apresentar alta eficiência em baixas doses, baixa toxicidade para mamíferos e amplo espectro de ação, embora muitos deles possam mostrar persistência prolongada no ambiente (Sprague et al., 1997).

O primeiro herbicida com esse mecanismo de ação disponível no mercado foi o chlorsulfuron, registrado em 1982 para ser utilizado em cereais (Saari et al., 1994). Cinco anos após o início do uso dos inibidores da ALS, foi constatado o primeiro caso de resistência de planta daninha a esse mecanismo de ação (Mallory-Smith et al., 1990), e sua incidência começou a aumentar em número tanto de locais como de espécies. A alta eficiência que possibilita a utilização em baixas doses é um dos fatores responsáveis pela rápida seleção de ecótipos de plantas daninhas resistentes (Sprague et al., 1997; Gazziero et al., 2006).

Geralmente, o mecanismo de resistência aos herbicidas inibidores da ALS é considerado como falta de sensibilidade da enzima ao herbicida, ou seja, ocorre alguma alteração no sítio de ligação herbicida-enzima (Haughn \& Somerville, 1990; Carvalho et al., 2004). Já os mecanismos de tolerância de culturas aos herbicidas inibidores da ALS são resultado de diferenças quanto à absorção, translocação (Meyer \& Muller, 1989; Leite et al., 1998) e degradação do produto antes que chegue ao local de ação (Brown et al., 1991; Leite et al., 1998). Esses mesmos mecanismos já foram observados como conferindo resistência aos inibidores da ALS em plantas daninhas (Neighbors \& Privalle, 1990; Cotterman \& Saari, 1992).

Embora haja muitos métodos de identificação da resistência (cultura de células, bactérias, determinação da atividade enzimática), o de maior precisão é o teste com aplicação do herbicida sobre a planta inteira (Hernandes et al., 2005). Enquanto os primeiramente citados são mais adequados para determinar o mecanismo de resistência por meio do comportamento fisiológico do herbicida na planta, o segundo permite a caracterização quantitativa da resistência pela determinação de variáveis diretas, como altura de plantas, $\mathrm{I}_{50}, \mathrm{DL}_{50}$, fitomassa fresca e seca, entre outros, que contribuem na determinação do desempenho e competitividade dessas plantas a campo (Brighenti et al., 2001; Eberhardt \& Noldin, 2002; Rampelotti et al., 2003b; Noldin et al., 2004).

A sagitária caracteriza-se como uma planta daninha que ocorre em altas infestações na maioria das áreas de cultivo de arroz irrigado, em Santa Catarina (Noldin et al., 2004). A ocorrência de populações de sagitária com resistência cruzada a herbicidas inibidores da ALS foi relatada no final da década de 1990, tanto para os herbicidas do grupo das sulfoniluréias como para pirimidinil thiobenzoatos (Noldin et al., 1999). Atualmente, constata-se a ocorrência de populações de sagitária resistente aos herbicidas inibidores da ALS em praticamente todos os municipios produtores de arroz irrigado em Santa Catarina, com carência de alternativas de controle eficientes.

Considerando a importância de elucidar $\mathrm{o}(\mathrm{s})$ mecanismo (s) envolvido (s) na resistência de Sagittaria montevidensis, principalmente para a recomendação de práticas de manejo mais eficientes e redução da pressão de seleção, o objetivo deste trabalho foi avaliar aspectos de nivel, local preferencial de absorção e a translocação do herbicida pirazosulfuron-ethyl.

\section{MATERIAL E MÉTODOS}

O experimento foi conduzido em casa de vegetação do Departamento de Fisiologia Vegetal da Universidade Federal de Pelotas RS. Os tratamentos foram compostos de doses exponenciais do herbicida pirazosulfuron-ethyl $\left(2^{0} \mathrm{x}, 2^{2} \mathrm{x}, 2^{4} \mathrm{x}, 2^{6} \mathrm{x}\right.$ e $2^{8} \mathrm{x}$, sendo $\mathrm{X}=$ dose usual de $20 \mathrm{~g}$ i.a. ha ${ }^{-1}$ ), aplicados individualmente na parte aérea e raiz, sobre plântulas de ecótipos resistente e suscetível, visando avaliar o sítio preferencial de absorção. A concentração-padrão foi considerada como $20 \mathrm{~g} \mathrm{ha}^{-1}$ de pirazosulfuron-ethyl, com lâmina teórica de água constante de $10 \mathrm{~cm}$ (solução $2^{\circ} \mathrm{x}$ ), calculando-se as demais a partir desta. Devido ao baixo percentual de germinação das sementes, a semeadura foi feita em bandejas separadas, com posterior transplante para as 
unidades definitivas, quando as plantas estavam com três a quatro folhas, sendo escolhidas plântulas de tamanho similar para todos os tratamentos e repetições. No momento do transplante as unidades experimentais já se encontravam inundadas com água pura, e foram mantidas nessa condição até o momento da aplicação dos tratamentos.

As unidades experimentais constaram de copos plásticos de $500 \mathrm{~mL}$ perfurados na lateral próximo ao fundo, contendo solo até $3 \mathrm{~cm}$ abaixo da borda. O experimento foi instalado em delineamento experimental de blocos casualizados, com quatro repetições. As unidades experimentais foram mantidas dentro de bandejas plásticas individuais, contendo água em altura de $1 \mathrm{~cm}$ inferior à altura do solo nas unidades experimentais durante uma semana após o transplante, a fim de garantir que todas as plantas se desenvolvessem corretamente, quando então ocorreu a aplicação dos tratamentos. Para aplicação na parte aérea, o solo da unidade experimental permaneceu totalmente coberto com camada de papel-alumínio revestido de papel-toalha, para evitar o contato da solução herbicida com o solo, e as folhas foram pinceladas com as respectivas soluções herbicidas, de forma a proporcionar cobertura total e homogênea da planta.

Para aplicação ao sistema radical, a água foi substituída pelas respectivas soluções herbicidas nas unidades cuja aplicação foi por via radical, sendo as demais mantidas em água pura. Nos tratamentos via raízes, a parte aérea das plantas não entrou em contato com o herbicida, pois no momento da aplicação se encontrava desenvolvida e projetada para fora da unidade experimental, sem contato com o solo. A metodologia foi aperfeiçoada para se assemelhar às condições de campo, onde o herbicida pirazosulfuron-ethyl é aplicado uma única vez sobre as plantas, mas permanece presente na lâmina de água durante longo período (Rampelotti et al., 2003a).

A água (aplicação via aérea) ou solução (aplicação ao sistema radicular) evaporada foi constantemente reposta, de forma a manter o nível próximo ao do solo das respectivas unidades experimentais. Além disso, a cada reposição nova solução era elaborada, não sendo utilizada solução de estoque. As plantas se desenvolveram durante 40 dias após o transplante (DAT), quando então foram avaliados a altura de planta, a fitomassa fresca e seca e o conteúdo de água. Após a medição da altura, as plantas foram cortadas rente ao solo e acondicionadas em sacos plásticos pequenos, lacrados e colocados no interior de caixa de poliestireno expandido contendo gelo, e levadas imediatamente ao laboratório, para aferição da massa em balança analítica e obtenção da fitomassa fresca (MF). Posteriormente, foram transferidas para sacos de papel e levadas à estufa de circulação forçada de ar a $60{ }^{\circ} \mathrm{C}$, até massa constante, quando então tiveram a massa novamente aferida, para obtenção da fitomassa seca (MS). O conteúdo de água foi calculado pela fórmula $100 *(\mathrm{MF}-\mathrm{MS} / \mathrm{MF})$. A análise de variância foi realizada pelo teste F a 5\% e, em caso de significância, foi efetuada análise de regressão. Para comparação de pares de médias, foi utilizado o teste da DMS em nivel de $5 \%$ de probabilidade.

\section{RESULTADOS E DISCUSSÃO}

As análises da altura de plantas do ecótipo resistente evidenciaram comportamento diferenciado em relação ao local de aplicação. A aplicação do herbicida na dose mais alta $\left(2^{8} \mathrm{x}\right)$ na parte aérea causou redução em torno de $20 \%$ na altura das plantas. Por outro lado, esse efeito não foi observado com aplicação nas raízes (Figura 1). Para o ecótipo suscetível, o controle de $100 \%$ da população foi obtido na dose de $2^{2} \mathrm{x}$ para ambas as formas de aplicação (parte aérea e raiz), não apresentando diferenças médias significativas. Mes mo não se alcançando controle total das plantas na menor dose, estas paralisaram o desenvolvimento, sendo a redução de altura em torno de $40 \%$ quando comparado com o ecótipo resistente, tanto para aplicação em parte aérea como em raízes (Figura 1). Bizzi \& Andres (2001) alcançaram controle de populações suscetiveis de sagitária, em campo, na dose comercial $\left(2^{\circ} \mathrm{x}\right)$, tanto no sistema de benzedura como por pulverização.

A fitomassa fresca, por outro lado, não sofreu efeito de doses do herbicida, mas sim do local de aplicação (Figura 2). O ecótipo resistente apresentou maior fitomassa fresca quando o pirazosulfuron-ethyl foi aplicado no sistema radical, quando comparado com aplicação na parte aérea, diferentemente do 
ecótipo suscetível, cuja fitomassa fresca foi maior quando a aplicação herbicida ocorreu na parte aérea das plantas (Figura 2). Leite et al. (1998) relatam que a absorção dos herbicidas inibidores da ALS via sistema radical não é tão limitada como na folha, ou seja, a baixa presença de substâncias lipídicas nas raízes, juntamente com a ausência de cutícula, torna mais fácil a absorção. Conseqüentemente, nas plantas suscetiveis o dano foi maior quando a aplicação do produto ocorreu na raiz, provavelmente devido à sua maior absorção pela planta, considerando que o movimento normalmente pode ocorrer tanto via xilema quanto floema. Por sua vez, o ecótipo resistente se mostrou menos sensivel quando a aplicação ocorreu nas raizes (Figura 2). Esse fato pode não ser o mecanismo de resistência, que, normalmente, para herbicidas inibidores da ALS é considerado como insensibilidade da enzima ao herbicida (Christoffoleti, 2001), mas provavelmente pode estar relacionado a ele, talvez como conseqüência indireta do conjunto de alterações ocorrido na planta. No ecótipo resistente, a via de absorção preferencial foi aérea, podendo resultar de alterações tanto da anatomia como da composição química da cutícula foliar (Ferreira, 2005). Esses dados são confirmados pela fitomassa seca, onde o ecótipo resistente mostrou maior fitomassa quando o herbicida foi aplicado nas raízes, independentemente do tratamento (Figura 3a). Por sua vez, a fitomassa seca do ecótipo suscetivel foi menor na dose de $2^{\circ} \mathrm{x}$ quando a aplicação ocorreu nas raízes (Figura $3 b$ ).

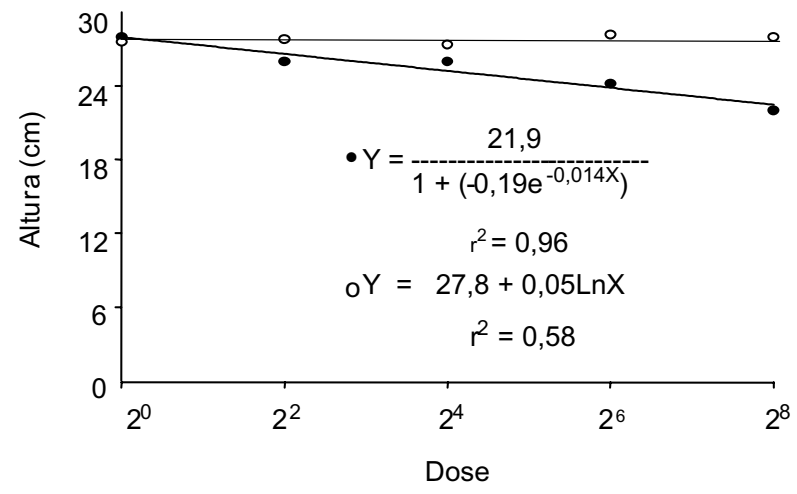

Figura 1 - Altura de parte aérea de plantas de S. montevidensis aos 40 DAT, em função de doses do herbicida pirazosulfuron-ethyl, aplicado em parte aérea ( ) e raiz (o) do ecótipo resistente (A). D x L x E $=5 \%$; CV =9,8\%.

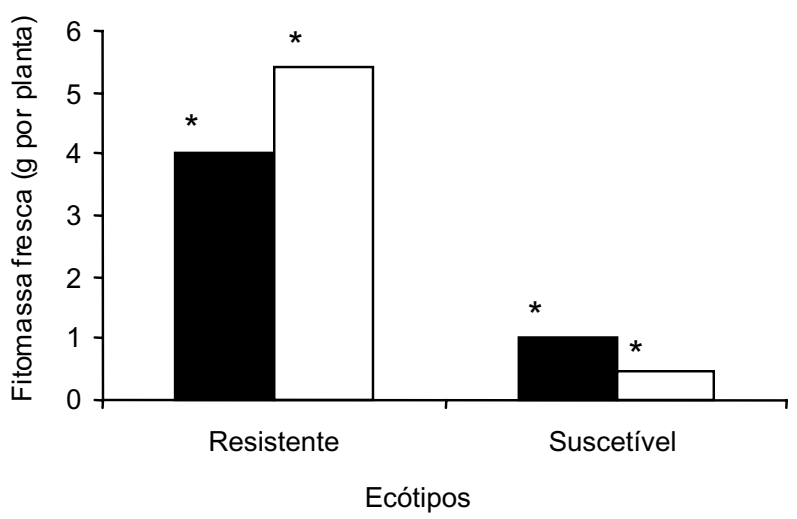

Figura 2 - Fitomassa fresca de parte aérea de plantas de $S$. montevidensis aos 40 DAT, em função de doses do herbicida pirazosulfuron-ethyl, aplicado em parte aérea $(\boldsymbol{\square})$ e raízes ( $\square$ ) dos ecótipos resistente e suscetível. L x E $=5 \%$; $\mathrm{CV}=29,0 \%$.
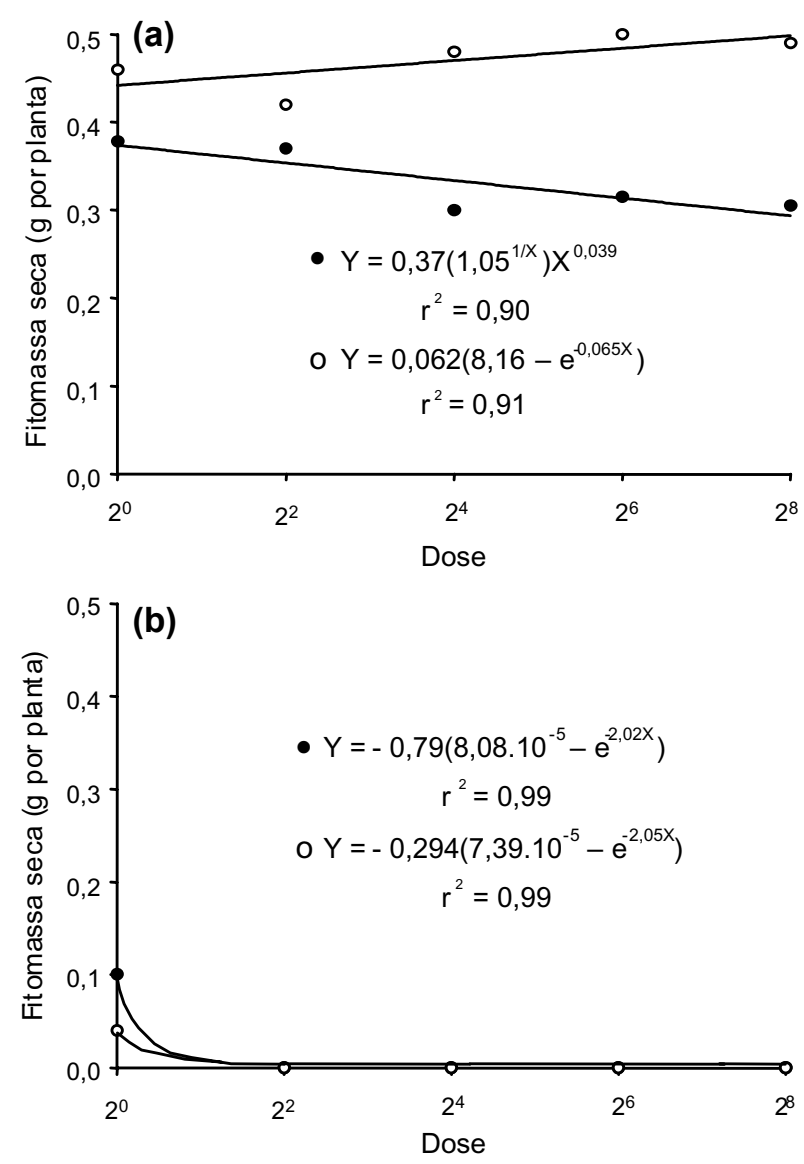

Figura 3 - Fitomassa seca de parte aérea de plantas de $S$. montevidensis aos 40 DAT, em função de doses do herbicida pirazosulfuron-ethyl, aplicado em parte aérea (•) e raiz (o) dos ecótipos resistente (a) e suscetível (b). D x L x E $=5 \% ; C V=30,7 \%$. 
De acordo com Vidal (2002), a absorção de herbicidas via foliar pode ser afetada pelo efeito do ambiente sobre a gota, pela densidade de plantas daninhas, pela disposição foliar e pela superfície atingida. No experimento conduzido em casa de vegetação, nenhum desses fatores foi diferenciado entre tratamentos, pois as plantas foram completamente pinceladas com a solução herbicida, não houve a formação diferencial de gotas (a cobertura foi continua), a densidade de plantas foi a mesma, a disposição foliar não foi considerada devido à modalidade de aplicação e a superficie atingida foi idêntica: a planta inteira. No caso de aplicação via radicular, as raízes permaneceram constantemente em contato com a solução herbicida em todas as unidades experimentais, não sendo a aplicação dos tratamentos fonte de erro.

O conteúdo de água das plantas foi alterado com o aumento da dose aplicada sobre o ecótipo resistente, incrementando em torno de $2 \%$ no ecótipo resistente em relação ao suscetivel com aplicação na parte aérea, e 1\% com aplicação nas raízes (Figura 4). No ecótipo suscetivel, só foi possivel avaliar o conteúdo de água na dose de $2{ }^{\circ} \mathrm{x}$, situando-se em torno de 89 - 91\% (dados não mostrados). Alterações no conteúdo de água como um dos primeiros sintomas de fitotoxicidade dos herbicidas inibidores da ALS foram observadas por

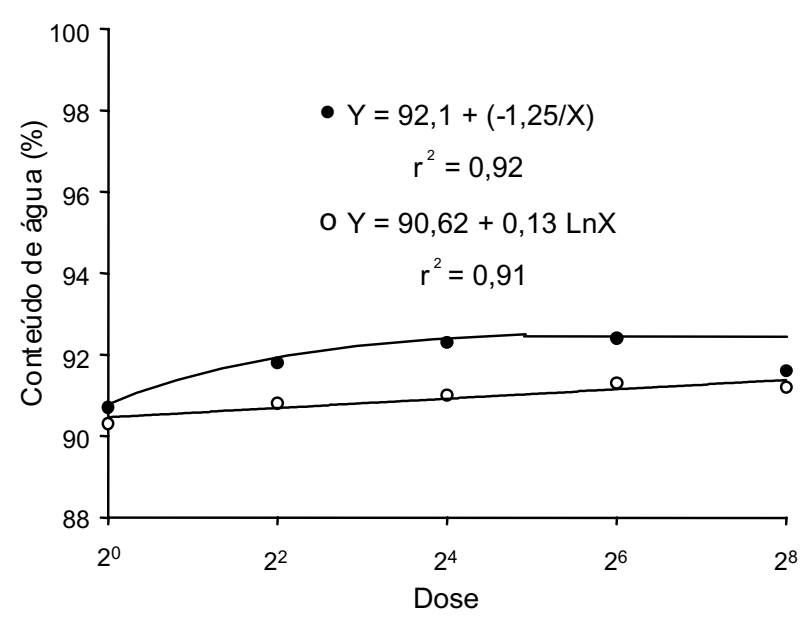

Figura 4 - Conteúdo de água de parte aérea de plantas de $S$. montevidensis aos 40 DAT, em função de doses do herbicida pirazosulfuron-ethyl, aplicado em parte aérea $(\bullet)$ e raiz (o) do ecótipo resistente (A).D x L x E $=5 \%$; CV =2,7\%.
Concenço et al. (2003), trabalhando com doses elevadas de penoxsulam. Estes autores observaram que a redução do conteúdo de água foi em função do incremento na dose, alcançando até $8 \%$ no sistema radical do arroz. Por outro lado, a parte aérea não sofreu alteração.

O conteúdo de água no tecido é um indicador de toxicidade de herbicidas às plantas (Brown, 1946; Minshall, 1960; Wort, 1964a); enquanto alguns herbicidas incrementam o conteúdo de água, outros reduzem, variando de uma espécie para outra (Wort, 1964b). Por sua vez, o conteúdo de água é muito sensivel, podendo sofrer alterações antes mesmo que outras variáveis sejam alteradas (Wort, 1964a).

Para que as diferenças quanto à absorção sejam caracterizadas, o mais adequado seria trabalhar com produto marcado radioativamente. No entanto, esta opção é limitada devido ao reduzido número de instituições autorizadas a trabalhar com produtos dessa natureza no Brasil.

Os resultados observados neste estudo fornecem evidências de que o ecótipo resistente de S. montevidensis estudado possui maior velocidade inicial percentual de germinação que o ecótipo suscetível. Além disso, o maior vigor do ecótipo resistente (Figura 5) pode ser atribuído em parte ao maior tamanho das sementes do ecótipo resistente, comparado com o suscetivel (Figura 6). Esses resultados estão de acordo, em parte, com o observado por Rampelotti et al. (2003a), os quais afirmaram não ter encontrado diferenças quanto a altura e fitomassa seca entre ecótipos resistente e suscetivel na análise de crescimento, mas encontraram diferenças quanto à área foliar, com vantagem para os ecótipos resistentes.

Rizzardi et al. (2002) discutem a hipótese de que ecótipos resistentes a herbicidas poderiam apresentar diferenças quanto à adaptabilidade em relação aos suscetiveis. Brighenti et al. (2001) não encontraram diferenças de adaptabilidade entre ecótipos resistente e suscetivel de Euphorbia heterophylla. Por sua vez, Melo et al. (2003a, b) e Concenço et al. (2003), estudando 44 ecótipos de capim-arroz (Echinochloa sp.) resistentes ao herbicida quinclorac, encontraram ecótipos resistentes com maior e com menor adaptabilidade que 
os ecótipos suscetíveis de referência. Thompson et al. (1994) não constataram diferenças em relação à adaptabilidade entre ecótipos " $R$ " e "S" aos inibidores da ALS. Gressel \& Segel (1990) concluíram que ecótipos de plantas resistentes às triazinas são normalmente menos competitivos que seus correspondentes suscetiveis, e Vargas et al. (2005), que o ecótipo resistente de Lolium multiflorum é menos competitivo que o suscetivel ao glifosate.

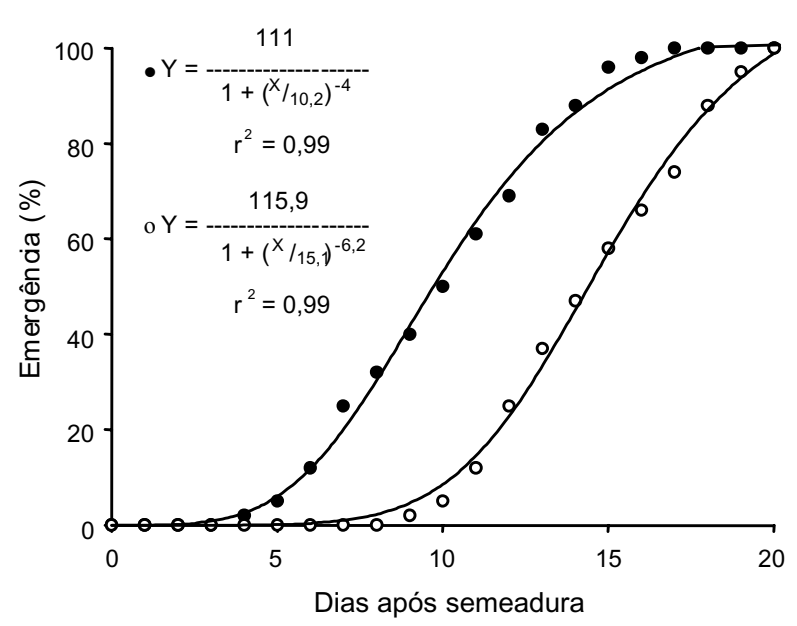

Figura 5 - Curva de emergência de S. montevidensis em função de dias após transplante $(\mathrm{T})$ e ecótipos $(\mathrm{E})$ resistente $(\bullet)$ e suscetível (o) em casa de vegetação. $\mathrm{T}$ x E $=5 \%$; $\mathrm{CV}=$ $8,1 \%$.

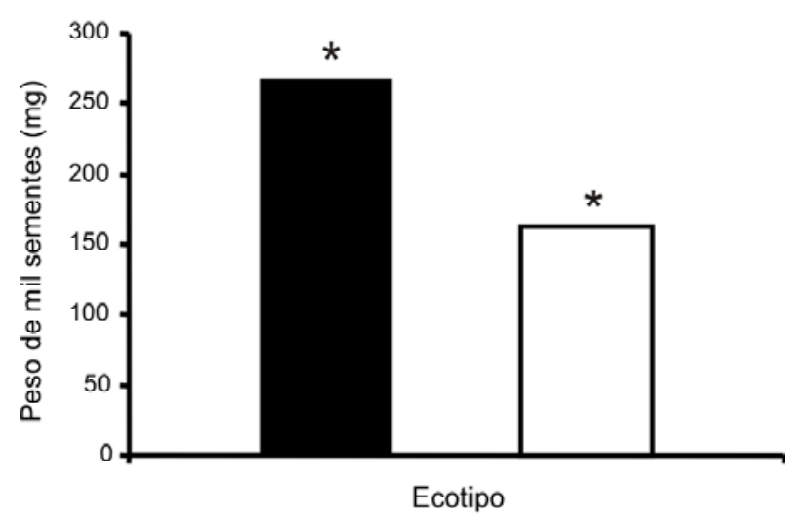

Resistente $\square$ Suscetivel

* Médias diferem a $1 \%$ pelo teste DMS.

Figura 6 - Peso de mil sementes de dois ecótipos de S. montevidensis, resistente e suscetível aos herbicidas inibidores da ALS. $\mathrm{E}=1 \%$; $\mathrm{CV}=5,2 \%$.
Como o ecótipo ecótipo "R" de S. montevidensis possui maior vigor de crescimento, seria capaz de ocupar a área primeiro e aumentar sua proporção ao longo do tempo, eliminando os individuos "S" menos vigorosos, inclusive influenciando a manutenção da proporção de plantas resistentes na população quando o agente selecionador é removido (Lopez-Ovejero et al., 2004). Esse problema poderia ser ainda mais grave quando se considera que $S$. montevidensis possui sementes relativamente leves e que a água de irrigação pode contribuir para a disseminação do ecótipo resistente (Fleck et al., 2004). Esse fato certamente contribuiu para disseminação do ecótipo resistente nas lavouras do Estado de Santa Catarina.

O ecótipo resistente de $S$. montevidensis apresentou emergência mais rápida, maior vigor inicial e altura final de plantas; a importância das raízes como sítio de absorção do herbicida pirazosulfuron-ethyl, no ecótipo resistente, foi diminuída, sendo este mais sensivel à aplicação na parte aérea; a maior adaptabilidade e as alterações em relação ao sítio de absorção do herbicida podem ser conseqüências indiretas, embora possam não ser a causa, do(s) fator(es) responsável(is) pela resistência de $S$. montevidensis aos herbicidas inibidores da ALS. Mais estudos em nível anatômico deverão ser conduzidos para esclarecer esse aspecto.

\section{LITERATURA CITADA}

BIZZI, A. F.; ANDRES, A. Controle de plantas daninhas no sistema pré-germinado de cultivo de arroz com herbicidas aplicados pulverizados e em benzedura. In: CONGRESSO BRASILEIRO DO ARROZ IRRIGADO, 2.; REUNIÃO TÉCNICA DA CULTURA DO ARROZ IRRIGADO, 24., 2001, Porto Alegre. Anais... Porto Alegre: IRGA, 2001. p. 564-567.

BRIGHENTI, A. M. et al. Análise de crescimento de biótipos de amendoin-bravo (Euphorbia heterophylla) resistente e suscetível aos herbicidas inibidores da ALS. Planta Daninha, v. 19, n. 1, p. 51-59, 2001.

BROWN, J. W. Water content in Kidney Bean Plants as affected by herbicides. Bot. Gaz., n. 107, p. 332-333, 1946.

BROWN, H. M. et al. Prospects for the biorational design of crop selective herbicides. In: BRIGHTIN CROP PROTECTION CONFERENCE - WEEDS, 1989, Farnham. Proceedings... Farnham: British Crop Protection Council, 1989. p. $847-856$. 
CARVALHO, S. J. P. et al. Identificação de biótipos de Bidens spp. resistentes aos inibidores da ALS através de teste germinativo. Planta Daninha, v. 22, p. 411-417, 2004.

CHRISTOFFOLETI, P. J. Bioensaio para determinação da resistência de plantas daninhas aos herbicidas inibidores da enzima ALS. Bragantia, v. 60, p. 261-265, 2001.

CONCENÇO, G. et al. Efeito do herbicida penoxsulam sobre o desenvolvimento inicial da cultivar de arroz BRS-Pelota. In: CONGRESSO DE INICIAÇÃO CIENTÍFICA, 13., 2004, Pelotas. Anais... Pelotas: Universidade Federal de Pelotas, 2004. CD-ROM.

COTTERMAN, J. C.; SAARI, L. L. Rapid metabolic inactivation is the basis for cross-resistance to chlorsulfuron in diclofop-methyl resistant Rigid Ryegrass (Lolium rigidum) biotype SR4/84. Pest. Biochem. Physiol., v. 43, p. 182-192, 1992.

EBERHARDT, D. S.; NOLDIN, J. A. Competitividade de sagitária em diferentes densidades de semeadura de arroz irrigado. In: CONGRESSO BRASILEIRO DA CIÊNCIA DAS PLANTAS DANINHAS, 23., 2002, Gramado.

Resumos... Londrina: Sociedade Brasileira da Ciência das Plantas Daninhas/Embrapa Clima Temperado, 2002. p. 207.

FERREIRA, E. A. Anatomia quantitativa, micromorfologia e sensibilidade a herbicidas em genótipos de cana-de-açúcar. 2005. $83 \mathrm{f}$. Dissertação (Mestrado em Botânica) - Universidade Federal de Viçosa, Viçosa, 2005.

FLECK, N. G. et al. Manejo e controle de plantas daninhas em arroz irrigado. In: VARGAS, L.; ROMAN, E. S. (Eds.). Manual de manejo e controle de plantas daninhas. Bento Gonçalves: Embrapa Uva e Vinho, 2004. p. 251-321.

GAZZIERO, D. L. P.; BRIGHENTI, A. M.; VOLL, E. Resistência cruzada da losna-branca (Parthenium hysterophorus) aos herbicidas inibidores da enzima acetolactato sintase. Planta Daninha, v. 24, p. 157-162, 2006.

GRESSEL, J.; SEGEL, L. A. Modelling the effectiveness of herbicide rotations and mixtures as strategies to delay or preclude resistance. Weed Technol., n. 4, p. 186-198, 1990.

HAUGHN, G. W.; SOMERVILLE, C. A mutation causing imidazolinone resistance maps to the Csr1 Locus of Arabidopsis thaliana. Plant Physiol., v. 92, p. 1081-1085, 1990.

HERNANDES, G. C.; VIDAL, R. A.; WINKLER, L. M. Levantamento de práticas agronômicas e distribuição geográfica de Bidens spp. resistentes aos herbicidas inibidores de ALS nos Estados do Rio Grande do Sul e do Paraná. Planta Daninha, v. 23, p. 677-682, 2005.
LEITE, C. R. F.; ALMEIDA, J. C. V.; PRETE, C. E. C. Aspectos fisiológicos, bioquímicos e agronômicos dos herbicidas inibidores da enzima ALS (AHAS). Londrina: 1998. $68 \mathrm{p}$.

LÓPEZ-OVEJERO, R. F.; CHRISTOFFOLETI, P. J.; VARGAS, L. Resistência de plantas daninhas a herbicidas. In: VARGAS, L.; ROMAN, E. S. (Eds.). Manual de manejo e controle de plantas daninhas. Bento Gonçalves: Embrapa Uva e Vinho, 2004. p. 185-214.

MALLORY-SMITH, C. A.; THILL, D. C.; DIAL, M. J. Identification of sulfonylurea herbicide-resistant prickly lettuce (Lactuca serriola). Weed Technol., v. 4, p. 163-168, 1990.

MELO, P. T. B. S. et al. Reação de ecótipos de capimarroz ao herbicida quinclorac. In: CONGRESSO BRASILEIRO DE ARROZ IRRIGADO, 3.; REUNIÃO DA CULTURA DO ARROZ IRRIGADO, 25., 2003, Balneário Camboriú. Anais... Itajaí: EPAGRI, 2003a. p. $438-440$.

MELO, P. T. B. S. et al. Determinação de metodologia de laboratório para identificação de sementes de capim-arroz resistente ao herbicida quinclorac. In: CONFERÊNCIA INTERNACIONAL DE ARROZ DE CLIMA TEMPERADO, 3., 2003, Punta del Este. Anais... Punta del Este: 2003b. CD-ROM.

MEYER, A. M.; MULLER, F. Triasulfuron and its selective behaviour in wheat and Lolium perenne. In: BRIGHTON CROP PROTECTION CONFERENCE - WEEDS, 1989, Farnham. Proceedings... Farnham: British Crop Protection Council, 1989. p. 441-448.

MINSHALL, W. H. Water moisture in plants. Can. J. Bot., n. 38 , p. 201-216, 1960.

NEIGHBORS, S.; PRIVALLE, L. S. Metabolism of primisulfuron by barnyardgrass. Pestic. Biochem. Physiol., v. 37 , p. $145-153,1990$.

NOLDIN, J. A; EBERHARDT, D. S.; KNOBLAUCH, R. Resistência de Sagittaria montevidensis a herbicidas: primeiras evidências. In: CONGRESSO BRASILEIRO DE ARROZ IRRIGADO, 1.; REUNIÃO DA CULTURA DO ARROZ IRRIGADO, 23., 1999, Pelotas. Anais... Pelotas: Embrapa-CPACT, 1999. p. 566-569.

NOLDIN, J. A.; EBERHARDT, D. S. Alternativas de controle químico de sagitária resistente aos herbicidas inibidores da ALS. In: CONGRESSO BRASILEIRO DE ARROZ IRRIGADO, 2.; REUNIÃO DA CULTURA DO ARROZ IRRIGADO, 24., 2001, Porto Alegre. Anais... Porto Alegre: IRGA, 2001. p. 574-578. 
NOLDIN, J. A. et al. Freqüência de plantas de Sagittaria montevidensis resistentes ao herbicida Only. In: CONGRESSO BRASILEIRO DA CIÊNCIA DAS PLANTAS DANINHAS, 24., 2004, São Pedro. Anais... Londrina: Sociedade Brasileira da Ciência das Plantas Daninhas, 2004. CD-ROM.

RAMPELOTTI, F. T. et al. Análise de crescimento de ecótipos de sagitária (Sagittaria montevidensis) resistente e suscetível a herbicidas inibidores da ALS. In: CONGRESSO BRASILEIRO DE ARROZ IRRIGADO, 3.; REUNIÃO DA CULTURA DO ARROZ IRRIGADO, 25., 2003. Balneário Camboriú. Anais... Itajaí: Epagri, 2003a. p. 483-485.

RAMPELOTTI, F. T. et al. Aspectos da biologia de ecótipos de Sagittaria montevidensis resistente a herbicidas inibidores da ALS. In: CONGRESSO BRASILEIRO DE ARROZ IRRIGADO, 3.; REUNIÃO DA CULTURA DO ARROZ IRRIGADO, 25., 2003. Balneário Camboriú. Anais... Itajaí: Epagri, 2003b. p. 486-488.

RIZZARDI, M. A. et al. Resistência de plantas aos herbicidas inibidores da acetolactato sintase. Planta Daninha, v. 20, n. 1, p. 149-158, 2002.

SAARI, L. L.; COTTERMAN, J. C.; THILL, D. C. Resistance do acetolactate synthase inhibiting herbicides. In: POWLES, S. B.; HOLTUM, J. A. M. (Eds.). Herbicide resistance in plants. Boca Raton: CRC Press, 1994. p. 83-139.
SHANER, D. L. Mechanisms of resistance to acelotactate synthase/acetohydroxyacid synthase inhibitors. In: CASELEY, J. C.; CUSSANS, G. W.; ATKINS, R. K. (Eds.) Herbicide resistance in weeds and crops. Oxford: Butterworth-Heinemann, 1991. p. 187-198.

SPRAGUE, C. L. et al. Palmer amaranth (Amaranthus palmeri) and common waterhemp (Amaranthus rudis) resistance to selected ALS-inhibiting herbicides. Weed Sci., n. 45 , p. 192-197, 1997.

THOMPSON, C. R.; THILL, D. C.; SHAFII, B. Growth and competitiveness of sulfonylurea -resistant and -susceptible kochia (Kochia scoparia). Weed Sci., n. 42, p. 172-179, 1994.

VARGAS, L. et al. Alteração das características biológicas dos biótipos de azevém (Lolium multiflorum) ocasionada pela resistência ao herbicida glyphosate. Planta Daninha, v. 23, n. 1, p. 153-160, 2005.

WORT, D. J. Effects of herbicides on plant composition and metabolism. In: AUDUS, L. J. (Ed.). The physiology and biochemistry of herbicides. New York: Academic Press, 1964a. p. 291-334.

WORT, D. J. Responses of plants to subletal concentrations of 2,4-D, without and with added minerals. In: AUDUS, L. J. (Ed.). The physiology and biochemistry of herbicides. New York: Academic Press, 1964b. p. 335-342. 